American Journal of Pharmaceutical Education 2017; 81 (1) Article 8.

\title{
RESEARCH
}

\section{Using Reflective Writing as a Predictor of Academic Success in Different Assessment Formats}

\author{
Cherie Tsingos-Lucas, ${ }^{\text {a,b }} \mathrm{PhD}$, BPharm, Sinthia Bosnic-Anticevich, ${ }^{\mathrm{a}} \mathrm{PhD}$, BPharm (Hons), \\ Carl R. Schneider, ${ }^{\text {P }}$ PD, BPharm (Hons), BN, Lorraine Smith, ${ }^{\text {a }}$ PhD, BA (Hons) \\ ${ }^{a}$ University of Sydney, Sydney, Australia \\ ${ }^{\mathrm{b}}$ Graduate School of Health, University of Technology, Sydney, Sydney, Australia \\ Submitted September 13, 2015; accepted December 10, 2015; published February 25, 2017.
}

\begin{abstract}
Objectives. To investigate whether reflective-writing skills are associated with academic success. Methods. Two hundred sixty-four students enrolled in a pharmacy practice course completed reflective statements. Regression procedures were conducted to determine whether reflective-writing skills were associated with academic success in different assessment formats: written, oral, and video tasks.

Results. Reflective-writing skills were found to be a predictor of academic performance in some formats of assessment: written examination; oral assessment task and overall score for the Unit of Study (UoS). Reflective writing skills were not found to predict academic success in the video assessment task.

Conclusions. Possessing good reflective-writing skills was associated with improved academic performance. Further research is recommended investigating the impact of reflective skill development on academic performance measures in other health education.
\end{abstract}

Keywords: reflective writing, reflection, academic performance, different formats of assessment, pharmacy education

\section{INTRODUCTION}

Research has shown that fostering reflective skills in health professional education can assist students to improve their clinical decision-making skills and enhance academic performance. ${ }^{1,2}$ Furthermore, enhancing reflective writing within health education has been at the forefront of the published literature in recent years. ${ }^{1,3-5}$ The ability to reflect on a deeper level is a desirable attribute for all health professionals. ${ }^{5-11}$ Reflective capacity is regarded as a skill to enhance learning from previous knowledge and experience in order to improve future clinical practice and clinical reasoning ${ }^{2,5,7,10,12}$ In particular, reflective writing can be used as a tool to enhance reflective capacity. ${ }^{9,13}$

Furthermore, in the medical field, awareness of the patient and of the health professional's own mental processes can be enhanced through the reflective-writing process. This can potentially improve clinical decisionmaking ability. ${ }^{14}$ In many cases, academic performance in health professional education is an indicator of effective

Corresponding Author: Cherie Tsingos-Lucas, University of Technology, Sydney, Graduate School of Health, 67 Thomas Street, Building 7, Level 4, Room 48, Ultimo, Sydney NSW 2007. Tel: + 61-2-9514-4275. E-mail: cherie.tsingoslucas@uts.edu.au clinical decision-making skills. Therefore, fostering reflective-writing skills may be a skill associated with improvement in clinical decision-making skills and academic performance.

Scholars posit that developing reflective-writing capacity will foster deeper learning and reflective thinking, which may lead learners to make better informed judgments and increase their ability to make optimal clinical decisions. ${ }^{1,5,8,9,15,16}$ Previous research has shown that using the skills of reflective writing improves academic and/ or clinical performance ${ }^{17,18}$ and is perceived by students as a valuable exercise to enhance reflective learning, thus potentially improving their performance of future clinical tasks. ${ }^{3,19}$ Furthermore, reflective narratives used in medical education have been shown to improve clinicalreasoning skills by nurturing the skills of observation, analysis, and interpretation. ${ }^{1,20}$ Thus, effective reflectivewriting skills may be beneficial for educating the pharmacy student and are fundamental for developing not only the reflective practitioner, but may assist with clinical reasoning and academic performance.

Reflective writing may take the forms of reflective statements, essays, portfolios, journals, diaries, or blogs. ${ }^{9}$ Evidence of support for the use of reflective writing in portfolios and journals in health professions are 


\section{American Journal of Pharmaceutical Education 2017; 81 (1) Article 8.}

numerous. ${ }^{14,21-30}$ These tools are used to foster students' thinking to challenge their biases, assumptions, and firmly held beliefs. ${ }^{14}$ Moreover, reflective-writing instruments in the form of statements have been used as an effective educational tool to assess medical and surgical resident learning in the medical curriculum. ${ }^{31}$ As some have advocated, using tools of reflective writing and working towards becoming a reflective practitioner should be considered a core attribute for professional development. ${ }^{1,7,18,20,25,32-34}$ Health professions are now insisting on students developing reflective-writing abilities to document continuing professional development and competencies. ${ }^{1,35}$

Despite the importance placed on reflective-writing skill development in health professional education, some researchers report "tension" between what students will write as an honest reflection and what they will write if a grade is associated with the task. This was illustrated in a Belgian study that investigated the perceptions of 142 midwifery students toward completing reflective writing exercises during their clinical training sessions. While most respondents perceived the reflective writing exercises as an effective learning tool, others reported that they wrote reflections that they believed would gain them a better assessment score. ${ }^{3}$ This was also illustrated in another qualitative study involving eight focus groups of second-year UK medical students, which reported similar issues regarding the "tension" caused by grading written reflections. ${ }^{36}$ Nevertheless, students from both studies perceived the exercises as a valuable learning experience that could enhance their performance of future clinical tasks and facilitate deeper understanding and learning. ${ }^{3,36}$ Similarly, a study introducing reflective-writing processes into an undergraduate pharmacy curriculum indicated that students perceived this type of learning as challenging. ${ }^{19}$ However, the majority of the students did perceive this learning exercise as valuable and indicated that the skill of reflective practice would be beneficial for improvement in other essential skill development including counseling and clinical decision-making. ${ }^{19}$

Therefore, it can be argued that effective reflectivewriting skills can be used as a tool to promote deeper understanding and learning, and thereby enhance clinical decision-making skills and improve academic performance. Research suggests that reflective ability is not necessarily an inherent skill, but can be taught through various strategies, models, and guidelines. ${ }^{37-44}$ Moreover, the development of reflective capacity has been described as necessary for experiential learning in the practice setting. ${ }^{3}$ Thus, developing and evaluating this fundamental skill should be a consideration in undergraduate and graduate health professions educational programs, ${ }^{9}$ and further scaffolding these skills in practice settings may benefit immediate and long-term reflective learning. $3,5,8,9,11,19$

Although reflective practice activities may enhance clinical reasoning skills, ${ }^{2,45}$ there is little published research investigating the effect of reflective-writing skills on particular types of assessments. The aim of this research was to explore the relationship between reflective writing and academic performance in a cohort of undergraduate pharmacy students.

\section{METHOD}

The sampling frame for this research was 264 secondyear undergraduate pharmacy students (92 male students, 172 female students) enrolled in a pharmacy practice course. The classroom or laboratory structure used in this course involved 10 groups of 26-27 students. Each group was facilitated by a practicing pharmacist clinical educator affiliated with the university. The pharmacy practice unit of study was an introductory unit that explored disease states and management options, including nonpharmacological recommendations. It focused on methods of delivering patient care to individual patients as well as to the wider community with an emphasis on primary care.

The data from this project were analyzed as part of a larger research project ${ }^{5}$ in which approval for the study was sought and granted by the University of Sydney Human Research Ethics Committee. Approval for integrating reflective activities into curriculum was also received from the school's Learning and Teaching Committee. As students were required as part of their regular course assessment to complete a reflective-writing task, all students in the second-year curriculum participated in this study.

In 2014, a reflective-writing module was introduced into a second-year undergraduate pharmacy curriculum as part of the Reflective Ability Clinical Assessment (RACA). ${ }^{5}$ We have described the process of the integration of reflective practice activities into the curriculum, and the structure of the Reflective Ability Clinical Assessment (RACA) and its evaluation in more detail in our previous paper. ${ }^{5}$ Briefly, The RACA aimed to enhance the reflective-thinking capacity of students and involved three components: a clinical scenario; a video podcast, and a reflective writing component. The RACA tasks required students to develop a role play, counsel another student, video tape the counseling session (for a maximum of five minutes), and then reflect on the experience through an introspective reflective-writing task. The reflective-writing task took the form of a reflective statement (Appendix 1). 


\section{American Journal of Pharmaceutical Education 2017; 81 (1) Article 8.}

Students were assigned one of 10 health problems that could be treated with nonprescription medication or nonpharmacological advice. These health problems included heartburn, sunburn, impetigo, worms, scabies, insomnia, head lice, traveler's diarrhea, chicken pox, and ticks. The students were then asked to research the problem (signs, symptoms, required referrals, advice), develop a typical clinical discussion/counseling session between a pharmacist and a patient, counsel (as the pseudo pharmacist) another student (serving as the pseudo patient) and write reflectively about the task. As part of the assignment, students were also encouraged to view and reflect on each other's videos to enhance selfand peer-reflection (Figure 1). The objective of the endof-semester oral examination was to assess effective counseling and clinical decision-making skills.

While the video podcast task (which counted $8 \%$ of the course grade) provided students with the opportunity to reflect on their counseling and clinical competency skills and those of a peer, it did not involve clinical decision-making skills as the student had prior knowledge of the clinical scenario. The main purpose of the video podcast task was to provide an opportunity for counseling practice prior to the end-of-semester oral assessment. No limit was placed on the number of podcasts recorded before uploading the best one to the Blackboard Learning Management System (LMS). Thus, this activity provided an opportunity for students to counsel each other several times. The video podcast counseling task was submitted mid-semester, along with the reflective statement.

The reflective statement consisted of guided questions (Appendix 1$)^{5}$ and was assessed by one external assessor to ensure grading consistency. The external assessor had expertise in the area of reflective writing and possessed extensive clinical pharmacy experience. The statements were assessed via a reflective rubric which was developed from Boud and colleagues, ${ }^{40}$ stages of reflection and Mezirow's ${ }^{46}$ categories of reflection. Elements of the rubric were also drawn from Wetmore and colleagues' reflective rubric, used in dental education (Table 1). ${ }^{47}$ The reflective statement counted $7 \%$ of the student's overall grade for the unit of study.

The oral assessment was a high-stakes examination completed at the end of the semester that accounted for $30 \%$ of the overall grade for the unit of study. Students were required to pass this assessment in order to pass the unit of study. While the topic area is provided earlier, the assessment does not provide students with prior knowledge of the case, patient background, signs and/or symptoms. In contrast to the video podcast assessment task, the oral assessment required the student to make appropriate clinical decisions based on gathering patient information during a five-minute timeframe.

After the oral assessment, all students from the cohort completed the end of semester written examination, which included both short-answer and multiple-choice

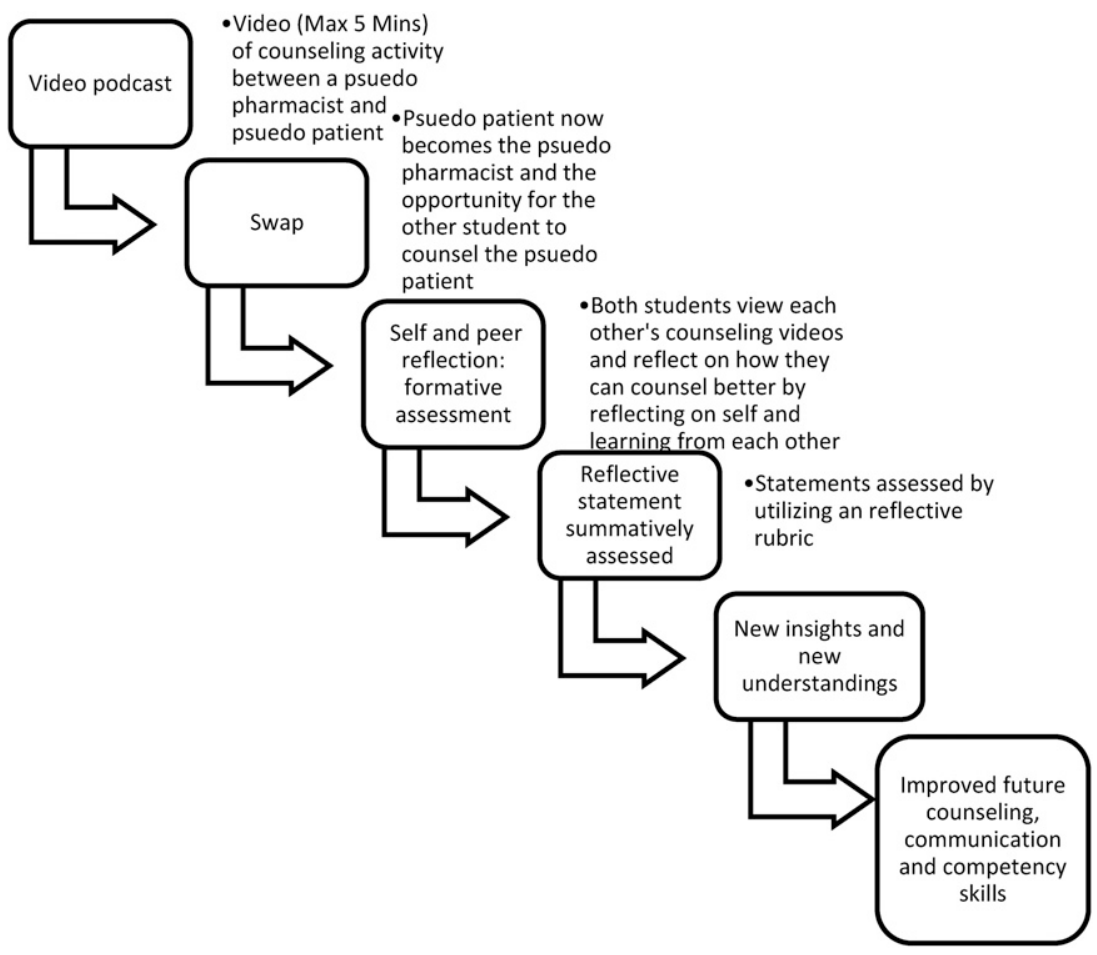

Figure 1. Utilization of video podcasts to enhance reflective capacity (self and peer reflection) of pharmacy students. ${ }^{5}$ 
American Journal of Pharmaceutical Education 2017; 81 (1) Article 8.

Table 1. Reflective Rubric to Assess Reflective Writing in Pharmacy Education ${ }^{11, a}$

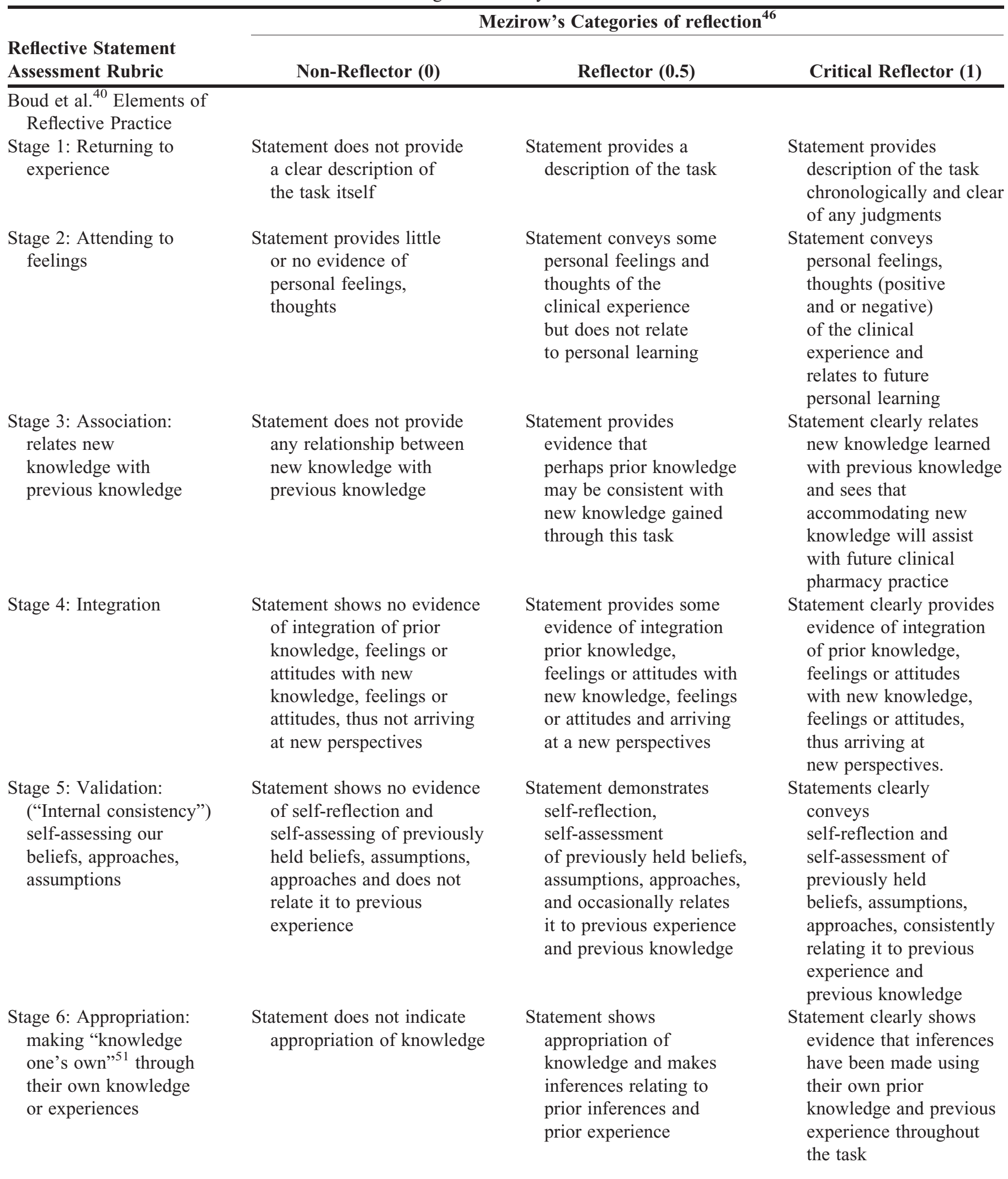




\section{American Journal of Pharmaceutical Education 2017; 81 (1) Article 8.}

Table 1. (Continued)

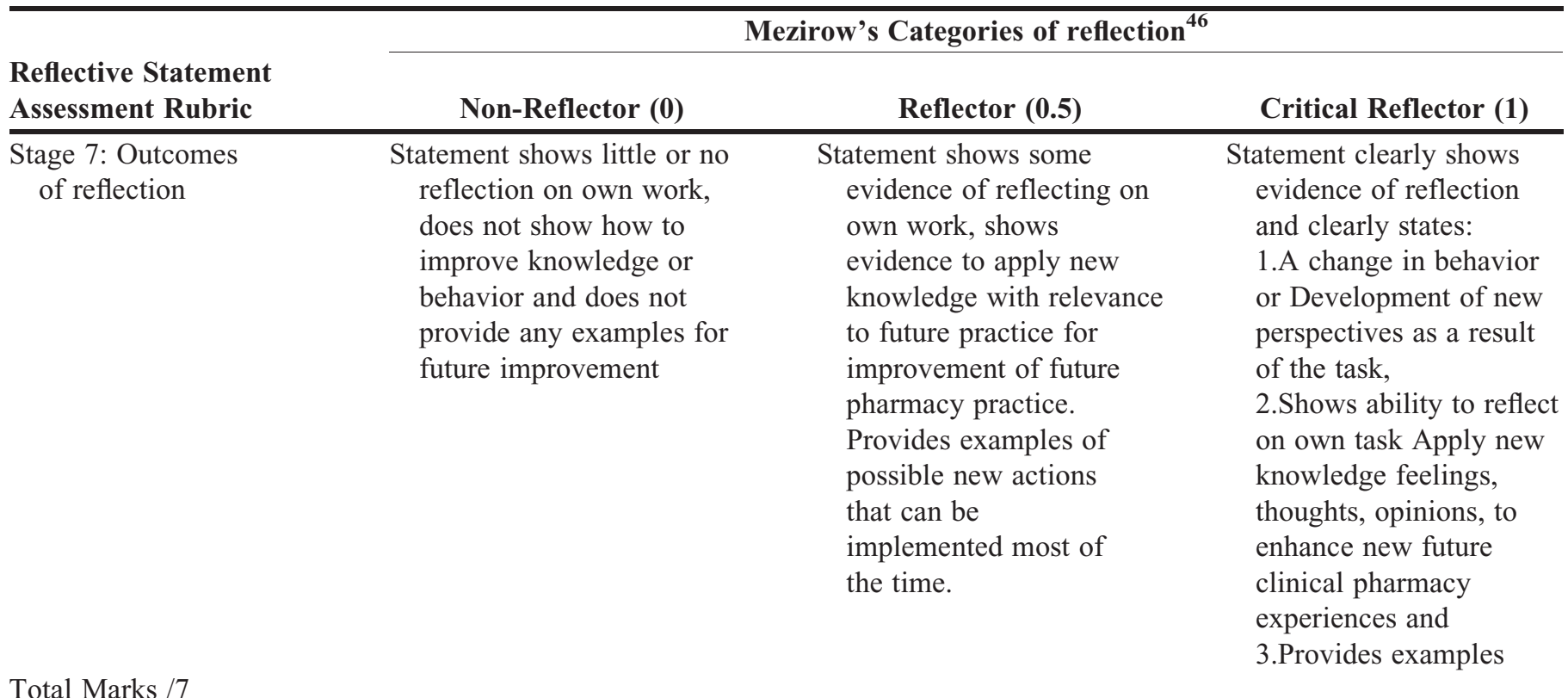

${ }^{a}$ Adapted from Boud et al $(1985)^{40}$ levels of reflection and Mezirow's $(1991)^{46}$ categories of reflection and elements drawn from the rubric utilized by Wetmore et al. ${ }^{47}$

questions (single best answer). This assessment accounted for $55 \%$ of the total grade for the unit of study.

Scores from all assessment and examination tasks were analyzed using SPSS, version 20 (IBM Corp., Armonk, NY, USA). Descriptive analyses were performed to provide an overview of the scores allocated for the four dependent variables (1) overall marks for the unit of study excluding the reflective statement scores; (2) written examination scores (including short answer and multiple-choice); (3) video podcasts score and (4) end of semester oral examination score. The predictor variable used the reflective-writing task scores. Simple regression procedures were employed to determine if reflective-writing skills predicted academic success in these different assessment formats. The reflective statement scores were excluded in the regression analyses, as these scores were used as a predictor variable. An adjusted overall score that excluded the reflective statement scores was used for this research. Significance was set at $p<.05$.

\section{RESULTS}

From a sample size of 264 undergraduate students enrolled in the Pharmacy Practice course, 259 (98\%) students completed the video podcasts counseling activity and a reflective writing task. Two hundred fifty-eight (98\%) students completed the written end-of-semester examination (Table 2).

The results from simple regression analyses explaining $14 \%$ of its variance $\left(\mathrm{R}^{2}=0.14\right)$ with overall academic achievement are as follows: (i) Are reflective writing skills a predictor of academic success in the Overall Marks for one unit of study?

Reflective writing skills was found to be a predictor of academic success in the Overall marks for the Unit of Study, $\mathrm{F}(1,256)=25.2, p<0.01$

(ii) Are reflective writing skills a predictor of academic success in the end of semester written examination?

Reflective writing skills was found to be a significant predictor of academic success in the end of semester written examination, $\mathrm{F}(1,256)=21.6, p<0.01$

(iii) Are reflective writing skills a predictor of academic success in the video counseling format of an assessment?

Reflective writing skills did not predict academic success in the video podcast counseling task, $(p=0.08)$.

(iv) Are reflective writing skills a predictor of academic success in the end of semester oral assessment?

Reflective writing skills was found to be a predictor of academic success in the end of semester Oral examination, $\mathrm{F}(1,257)=8.5, p<0.01$

\section{DISCUSSION}

In this study we examined the predictive relationship between reflective-writing skills and academic performance in four formats of assessment. The significant findings suggest that possessing reflective-writing skills is a predictor of academic success on the written examination and in the end-of-semester oral assessment. Interestingly, 


\section{American Journal of Pharmaceutical Education 2017; 81 (1) Article 8.}

Table 2. Descriptive Statistics: Scores for Different Formats of Assessment in a Second Year Undergraduate Pharmacy Curriculum

\begin{tabular}{|c|c|c|c|c|}
\hline & $\mathbf{N}$ & Minimum & Maximum & Mean (sd) \\
\hline Total Reflective Rubric Score (range: $0-7$ ) & 259 & 2.0 & 7.0 & $4.8(1.2)$ \\
\hline Overall Mark UoS exclusive of reflective marks (range: 0-138) & 258 & 51.4 & 111.5 & $86.5(11.5)$ \\
\hline Total Video Podcast Score (range 0-8) & 259 & 0.0 & 8.0 & $6.2(1.4)$ \\
\hline Total Oral End of Semester Score (range: 0-30) & 259 & 0.0 & 30.0 & $23.1(6.2)$ \\
\hline
\end{tabular}

reflective-writing skills were not a predictor of academic success in the video podcast assessment task. There are two possible explanations for this. First, research has shown that reflective-writing skills may enhance decision-making skills. ${ }^{48}$ Assessing the video podcast did not require the student to make any "on the spot" clinical decisions as the student had thoroughly researched the case prior to the counseling session. Conversely, the end-of-semester oral assessment did require students to demonstrate their clinical decision-making skills. Second, the video podcast assessment task was completed midsemester, prior to writing the reflective statement, and perhaps this contributed to the nonsignificant result, as reflection on that task was completed later. This study reported reflective writing had a stronger association with the written component compared to the oral assessment task. This may have been due to the fact that written skills were involved in completing the reflective task. In contrast, there were no written skills involved in completing the oral assessment.

These results, although significant, do not indicate a particularly strong effect size (14\% of its variance with overall academic achievement). It is possible that the traditional assessment modalities that are employed in pharmacy education are by and large not directly assessing reflective skills. If educators wish to develop this skill in the health professions, we need to address this in our assessment practices. ${ }^{11}$ Furthermore, the low effect size could be due to more specific details of the assessment strategies and to grades being allocated to content knowledge, written, and verbal communication skills compared to grades allocated specifically for reflective ability. The limitations of this study were that it involved only one course in an undergraduate curriculum at a single university and that it only involved pharmacy students.

This study advances understanding from previous research in the area of reflective learning of health professionals and the importance of considering the integration of reflective-writing skills into medical and other health professions educational curricula. Pharmacy students are not a homogenous group of future health professionals and this is also the case with the medical and other health professions. The use of reflective tools has been shown to improve decision-making skills. ${ }^{45}$ Furthermore, it has been suggested that tools which encourage the reflective process allow for continuous evaluation of learning and development ${ }^{48}$ as it encourages critiquing of practice, ${ }^{49}$ thus developing the health professional into a reflective practitioner. ${ }^{49}$ The findings from this study support the integration of reflective writing into health professional education.

Perhaps the greatest pedagogical challenge for educators of health professionals is how we can help them to write reflectively. Fostering students' reflective writing skills may be one solution to further developing their critical-thinking and problem-solving skills so they will be able to make better informed clinical judgments. Reflective-writing skills are not necessarily inherent and therefore may be developed through inclusion in health care education programs. ${ }^{20,38}$ For this to occur, a reflective framework or model may need to be further developed by health professional education systems to provide a springboard for fostering effective reflective writing. ${ }^{9}$ Ideally these skills should develop over the course of the degree; therefore, time allocated within the curriculum to foster these skills may be a necessary consideration for educators. ${ }^{9}$ Moreover, evaluating the effectiveness of such a fundamental skill through reflective rubrics may further enhance reflective capacity, particularly if reflective rubrics are provided to students prior to reflective-writing activities. ${ }^{11}$ Also, well-designed reflective rubrics may assist in providing appropriate guidance for desired learning outcomes, such as enhanced reflective capacity. ${ }^{11,50}$

Evidence from this study supports the notion that reflective-writing skills may be associated with improvement in pharmacy students' clinical decision-making capacity and academic performance. It therefore stands to reason that further research into the effects of various reflective activities in other areas of health education, where effective clinical-reasoning ability is also an important attribute, should be considered.

\section{CONCLUSIONS}

This study suggests that developing reflectivewriting skills in undergraduate pharmacy students may be associated with improved academic performance. As 


\section{American Journal of Pharmaceutical Education 2017; 81 (1) Article 8.}

these results may be specific for one educational setting, namely, pharmacy, we must be mindful that these findings may not translate to other learning environments or health professions. However, as reflective activities and tools appear to embed several health educational programs worldwide, further research in how reflective writing impacts on academic performance measures in other health disciplines is recommended. If reflective writing encourages a broader thinking process, it stands to reason that all health professional education programs should consider this element across curricula and into clinical environments.

\section{REFERENCES}

1. Wald HS, Reis SP. Beyond the margins: reflective writing and development of reflective capacity in medical education. $J$ Gen Intern Med. 2010;25(7):746-749.

2. Mamede S, Schmidt HG, Penaforte JC. Effects of reflective practice on the accuracy of medical diagnoses. Med Educ. 2008;42 (5):468-475.

3. Embo MPC, Driessen E, Valcke M, Van Der Vleuten CPM. Scaffolding reflective learning in clinical practice: A comparison of two types of reflective activities. Med Teach. 2014;36(7):602-607. 4. McKay FH, Dunn M. Student reflections in a first year public health and health promotion unit. Reflect Pract. 2015:1-12. 5. Tsingos-Lucas C, Bosnic-Anticevich S, Schneider CR, Smith L. The effect of reflective activities on reflective thinking ability in an undergraduate pharmacy curriculum. Am J Pharm Educ. 2016;80(4): Article 65.

6. Tsang AKL, Walsh LJ. Oral health students' perceptions of clinical reflective learning - relevance to their development as evolving professionals. Eur J Dent Educ. 2010;14(2):99-105.

7. Mann K, Gordon J, MacLeod A. Reflection and reflective practice in health professions education: a systematic review. Adv Health Sci Educ. 2009;14(4):595-621.

8. Tsingos C, Bosnic-Anticevich S, Smith L. Learning styles and approaches: can reflective strategies encourage deep learning? Curr Pharm Teach Learn. 2015;7(4):492-504.

9. Tsingos C, Bosnic-Anticevich S, Smith L. Reflective practice and its implications for pharmacy education. Am J Pharm Educ. 2014;78 (1):Article 18.

10. Tsingos C. Reflective practice: learning from experience. $J$ Pharm Pract Res. 2013;43(3):249-250.

11. Tsingos C, Bosnic-Anticevich S, Lonie JM, Smith L. A model for assessing reflective practices in pharmacy education. Am J Pharm Educ. 2015;79(8):Article 124.

12. Cutrer WB, Sullivan WM, Fleming AE. Educational strategies for improving clinical reasoning. Curr Probl Pediatr Adolesc Health Care. 2013;43(9):248-257.

13. Wald HS, Borkan JM, Taylor JS, Anthony D, Reis SP. Fostering and evaluating reflective capacity in medical education: developing the REFLECT rubric for assessing reflective writing. Acad Med. 2012;87(1):41-46.

14. Hobson EH, Johnston PE, Spinelli AJ. Staging a reflective capstone course to transition PharmD graduates to professional life. Am J Pharm Educ. 2015;79(1):Article 14.

15. Abrahams K, Brady C. Graduate reflective practice program: were long-term objectives achieved? J Med Imag Rad Sci. 2013;44 (4):203-208.
16. Lonie JM, Dolinsky D. Enhancing metacognitive skills using written narratives: An analysis of pharmacy student's negative health behaviors in a behavioral pharmacy class. Am J Pharm Educ. 2002;66 (3):273-276.

17. Chang M-M, Lin M-C. The effect of reflective learning e-journals on reading comprehension and communication in language learning. Comput Educ. 2014;71(0):124-132.

18. Embo M, Driessen E, Valcke M, van der Vleuten CPM. Relationship between reflection ability and clinical performance: a cross-sectional and retrospective-longitudinal correlational cohort study in midwifery. Midwifery. 2015;31(1):90-94.

19. Tsingos-Lucas C, Bosnic-Anticevich S, Smith L. A retrospective study on students' and teachers' perceptions of the Reflective Ability Clinical Assessment. Am J Pharm Educ. 2016;80(6):Article 101. 20. Karkabi K, Wald HS, Cohen Castel O. The use of abstract paintings and narratives to foster reflective capacity in medical educators: a multinational faculty development workshop. Med Human. 2014;40(1):44-48.

21. Saltman DC, Tavabie A, Kidd MR. The use of reflective and reasoned portfolios by doctors. J Eval Clin Pract. 2012;18(1): 182-185.

22. Snadden D, Thomas ML. Portfolio learning in general practice vocational training - does it work? Med Educ. 1998;32(4):401-406. 23. Sendall MC, Domocol ML. Journaling and public health education: thinking about reflecting. Educ Train. 2013;55(1):52-68. 24. Black PE, Plowright D. Exploring pharmacists' views about the contribution that reflective learning can make to the development of professional practice. Int J Pharm Pract. 2007;15(2):149-155.

25. Mathers NJ, Challis MC, Howe AC, Field NJ. Portfolios in continuing medical education - effective and efficient? Med Educ. 1999;33(7):521-530.

26. Plaza CM, Draugalis JR, Slack MK, Skrepnek GH, Sauer KA. Use of reflective portfolios in health sciences education. Am J Pharm Educ. 2007;71(2):Article 34.

27. Kostrzewski AJ, Dhillon S, Goodsman D, Taylor KMG. The impact of portfolios on health professionals' practice: a literature review. Int J Pharm Pract. 2008;16(6):339-345.

28. Goodyear HM, Bindal T, Wall D. How useful are structured electronic Portfolio templates to encourage reflective practice? Med Teach. 2013;35(1):71-73.

29. Sandars J. The use of reflection in medical education: AMEE Guide No. 44. Med Teach. 2009;31(8):685-95.

30. Thorpe K. Reflective learning journals: from concept to practice. Reflect Pract. 2004;5(3):327-343.

31. Monaghan SF, Blakely AM, Richardson PJ, Miner TJ, Cioffi WG, Harrington DT. The reflective statement: a new tool to assess resident learning. J Surg Res. 2012;178(2):618-622.

32. Friedman BDM, Davis MH, Harden RM, Howie PW, Ker J, Pippard MJ. AMEE medical education guide no. 24: portfolios as a method of student assessment. Med Teach. 2001;23(6):535-551. 33. McNamara KP, Duncan GJ, McDowell J, Marriott JL. Community pharmacists' preferences for continuing education delivery in Australia. J Contin Educ Health Prof. 2009;29(1):52-57. 34. Reis SP, Wald HS, Monroe AD, Borkan JM. Begin the BEGAN (The Brown Educational Guide to the Analysis of Narrative) - A framework for enhancing educational impact of faculty feedback to students' reflective writing. Patient Educ Couns. 2010;80(2): 253-259.

35. Tan K, Cashell A, Bolderston A. Encouraging reflection: do professional development workshops increase the skill level and use of reflection in practice? J Radiother Pract. 2012;11(3):135-144. 


\section{American Journal of Pharmaceutical Education 2017; 81 (1) Article 8.}

36. Vivekananda-Schmidt P, Marshall M, Stark P, Mckendree J, Sandars J, Smithson S. Lessons from medical students' perceptions of learning reflective skills: a multi-institutional study. Med Teach. 2011;33(10):846-850.

37. Russell T. Can reflective practice be taught? Reflect Pract. 2005;6(2):199-204.

38. Brockbank A, McGill I. Facilitating Reflective Learning in Higher Education. 2nd ed. Berkshire, England: Society for Research into Higher Education and Open University Press; 2007.

39. Bernard AW, Gorgas D, Greenberger S, Jacques A, Khandelwal $\mathrm{S}$. The use of reflection in emergency medicine education. Acad Emerg Med. 2012;19(8):978-982.

40. Boud D, Keogh R, Walker D. Promoting Reflection in Learning: A Model. Reflection: Turning Experience into Learning. London, Kogan Page; New York, Nicols Pub; 1985:18-40.

41. Schön DA. Educating the Reflective Practitioner. San Francisco, CA: Jossey-Bass; 1987.

42. Brookfield SD. Becoming a Crtically Reflective Teacher. San Francisco, CA: Jossey-Bass; 1995.

43. Moon J. Reflective Journals: A Handbook for Reflective Practice and Professional Development. 2nd ed. London: Routledge Falmer; 2006.
44. Johns C. Guided Reflection. Reflective Practice in Nursing. Oxford: Blackwell Scientific; 1994.

45. Ajjawi R, Loftus S, Schmidt H, Mamede S. Clinical reasoning: the nuts and bolts of clinical education. In Clinical Education in the Health Professions. Delany C, Molloy C (eds): Chatswood, NSW: Elsevier; 2009.

46. Mezirow J. Transformative Dimensions of Adult Learning. San Francisco, CA: Jossey-Bass; 1991.

47. Wetmore AOK, Boyd LD, Bowen DM, Pattillo RE. Reflective blogs in clinical education to promote critical thinking in dental hygiene students. J Dent Educ. 2010;74(12):1337-1350.

48. Sen BA. Reflective writing: a management skill. Library Manage. 2010;31(1/2):79-93.

49. Schon D. The Reflective Practitioner: How Professionals Think In Action. Gower House, England: Ashgate Publishing Ltd; 1995.

50. Coulehan J, Granek IA. Commentary: "I hope I'll continue to grow": rubrics and reflective writing in medical education. Acad Med. 2012;87(1):8-10.

51. Chirema KD. The use of reflective journals in the promotion of reflection and learning in post-registration nursing students. Nurse Educ Today. 2007;27(3):192-202.

Appendix 1. Reflective Statement ${ }^{5}$

Reflective Statement (2 x A4 page, Times New Roman, 12 Font)

The reflective statement should demonstrate an ability to undertake reflection and critical analysis. In achieving this, this personal statement should reflect upon, among other things:

1. What were your thoughts, feelings and beliefs towards the task and were they altered by performing the task?

2. How did you prepare for this task?

3. What happened in the task?

4. Your strengths or skills that you found applicable to the task?

5. Did you encounter any problems (personal, weaknesses, barriers addressed) whilst undertaking the task and if so, how did you overcome them?

6. What have you learned as a result of this task and how may it benefit you in the future? 